\title{
Exposure to prenatal infection and risk of schizophrenia
}

\author{
Alan S. Brown ${ }^{1,2 *}$ \\ 1 Department of Psychiatry, Columbia University College of Physicians and Surgeons, New York State Psychiatric Institute, New York, NY, USA \\ 2 Department of Epidemiology, Columbia University Mailman School of Public Health, New York, NY, USA
}

\section{Edited by:}

Sulie L. Chang, Seton Hall University, USA

\section{Reviewed by:}

Herb Lachman, Albert Einstein College of Medicine of Yeshiva University, USA

Mikhail Pletnikov, Johns Hopkins University, USA

\section{${ }^{*}$ Correspondence:}

Alan S. Brown, New York State

Psychiatric Institute, 1051 Riverside

Drive, Unit 23, New York, NY 10032,

USA.

e-mail:asb11@columbia.edu
We provide a brief review of findings supporting a role for prenatal infection in the etiology of schizophrenia. Our group and others have conducted birth cohort studies to address whether in utero exposure to infectious agents, prospectively documented by biomarker assays of archived maternal sera, and by detailed obstetric records, confer an increased risk of schizophrenia in adult offspring. Prenatal exposure to influenza, elevated toxoplasma antibody, rubella, genital-reproductive infections, and other infections have been associated with an increased risk of schizophrenia among offspring. Animal models have supported these epidemiologic findings by revealing that maternal immune activation causes phenotypes analogous to those found in patients with schizophrenia. Given that exposure to microbial agents are preventable or treatable, they suggest that interventions to diminish the incidence of infection during pregnancy have the potential to prevent an appreciable proportion of schizophrenia cases. Given the clear genetic component to schizophrenia, future studies should include investigations of interactions between prenatal infection and susceptibility genes in the pathogenesis of schizophrenia.

Keywords: schizophrenia, infection, influenza, epidemiology, toxoplasmosis, rubella, birth cohort

\section{INTRODUCTION}

Schizophrenia is a complex neuropsychiatric disorder which has both genetic and environmental components. Support for a role of genes in the disorder derives from twin, family, and adoption studies (Riley and Kendler, 2005). The strongest evidence among these study designs is the twin study, in which the concordance rate of a disorder is compared between monozygotic (MZ) and dizygotic (DZ) twins. These studies have demonstrated marked increases in twin concordance in MZ compared to DZ twins. Since MZ twins are believed to share all of their genes, compared to $D Z$ twins, who share only about $50 \%$ of their genes, these studies are consistent with an important role of genes in schizophrenia. In addition, numerous studies have identified strong evidence for associations between several susceptibility alleles and schizophrenia (Gejman et al., 2011).

Notably, however, the concordance rate for schizophrenia in MZ twins is approximately $50-60 \%$ indicating that environmental factors likely play a significant role in susceptibility to this disorder (Riley and Kendler, 2005). Moreover, twin studies do not yield precise measures of heritability because the additive component of the model, on which that estimate is based, includes geneenvironment interaction (Schwarts and Susser, 2006). Hence, increased attention is being paid to the study of environmental factors in schizophrenia, in order to account for the unexplained heritability. It is also worth noting, however, that recent work suggests that at least some of this unexplained genetic risk may be a result of copy number variants (CNVs) and other rare variants, which can arise de novo (Buizer-Voskamp et al., 2011), and it is generally believed that whole genome sequencing will identify many if not most of these rare alleles.

Much of the work on environmental exposures in schizophrenia has focused on prenatal infection. Initial clues indicated that births during the winter and spring months and in urban areas were related to an increased risk of the disorder (Brown and Derkits, 2010). This suggested that infections, which vary by season and spread more quickly in urban regions, may contribute to these associations. Schizophrenia is generally believed to have a strong neurodevelopmental component to its etiology (Waddington, 1993), and congenital infection has been well documented as a cause of known neuropsychiatric disorders (Remington and Klein, 2006). Hence, epidemiologic investigations have examined the role of prenatal infection in schizophrenia.

Initial studies utilized ecologic data on influenza and other epidemics in populations to define the timing of exposure during pregnancy (for review, see Brown and Derkits, 2010). While several papers suggested potential associations between influenza epidemics and schizophrenia among those who were in utero during the second trimester of pregnancy, a number of subsequent studies failed to replicate these findings. These studies were limited, however, by imprecise measures of exposure given that influenza infection was not documented in individual pregnancies. Hence, our group and others have initiated more refined approaches including birth cohort studies to address whether prenatal infection is a risk factor for schizophrenia.

\section{BIRTH COHORT STUDIES OF PRENATAL INFECTION AND SCHIZOPHRENIA}

Birth cohort studies offer numerous advantages in research on risk factors for psychiatric disorders such as schizophrenia. A birth cohort is a collection of individuals or pregnancies from a specific time period and place, recruited at the time of, or prior to birth (Rothman and Greenland, 1998). In a typical birth cohort study, baseline data and often biological specimens are collected during pregnancy, birth, and the neonatal period, and are archived 
for future studies, and the cohort is followed over time for the development of the disorder of interest. Birth cohort studies offer numerous advantages over ecologic studies, in that the exposure of interest, in this case infection, can be documented in individual pregnancies and related to the outcome, specifically schizophrenia. These studies can also capitalize on serologic biomarkers of infection by assays for specific antibodies or measures of immune function. Furthermore, most of these studies do not rely on maternal recall of the infection after the pregnancy, which can lead to inaccurate or biased reporting, particularly if the outcome is assessed after the diagnosis of schizophrenia is made. Rather, exposures can be documented prospectively, which provides more accurate measurement of the infection and cannot be influenced by the outcome since it occurs long after assessment of the exposure. We first review seroepidemiologic studies of infection and schizophrenia, and then discuss other birth cohort studies that have examined this question.

\section{SEROEPIDEMIOLOGIC STUDIES OF PRENATAL INFECTION}

In the Child Health and Development Study (CHDS) birth cohort, our group has investigated the relationship between several prenatal infections and schizophrenia risk (Brown and Derkits, 2010). An advantage of this cohort was the use of archived maternal serum specimens which could be assayed for antibody to different infections that were plausibly considered to represent putative risk factors for schizophrenia. All subjects were born from 1959 to 1967 in Alameda County, California and were followed up, in collaboration with the Kaiser Permanente Division of Research and the CHDS cohort, using electronic databases, structured research interviews, and psychiatric records. Two other studies have investigated in utero infection and schizophrenia using archived biospecimens, the Collaborative Perinatal Project (Buka et al., 2001a), which was recruited during the same birth years as the CHDS, and also capitalized on maternal serum specimens, and a study from a Danish cohort, which had filter paper blood spots collected within the first week of life (Mortensen et al., 2007).

These studies have yielded evidence for a relationship between several infectious agents and immune biomarkers and schizophrenia risk. In the CHDS birth cohort, we demonstrated that exposure to influenza during early to mid-pregnancy was related to a threefold increased risk of schizophrenia among offspring (Brown et al., 2004a). In this cohort, we also demonstrated that elevated IgG antibody to Toxoplasma gondii ( T. gondii) was related to a greater than twofold elevation of schizophrenia risk (Brown et al., 2005). This finding was essentially replicated in the Danish study mentioned above, in which increased IgG antibody to this infection in infant filter paper blood was related to increased schizophrenia risk (Mortensen et al., 2007). In a study of maternal cytokines, our group demonstrated that maternal levels of interleukin-8 (IL-8) was increased twofold in pregnancies that led to schizophrenia, compared to healthy controls (Brown et al., 2004b). In the CPP cohort, maternal exposure to the cytokine tumor necrosis-factor alpha (TNF-alpha) was related to an increased risk of schizophrenia (Buka et al., 2001b). Both the CPP and CHDS birth cohorts have investigated the relationship between maternal antibody levels to herpes simplex viruses (HSV) and schizophrenia.
In two studies from the CPP, maternal HSV-2 IgG antibody levels, and seropositivity to this infection, respectively, were related to an elevated risk of schizophrenia (Buka et al., 2001a, 2008). These findings were not replicated in the CHDS birth cohort (Brown et al., 2006), although they were replicated by a recent study on filter paper blood spots from Denmark (Mortensen et al., 2010).

In the Rubella Birth Defects Evaluation Project (RBDEP), a birth cohort with serologic documentation of prenatal exposure to rubella, we demonstrated that the prevalence of schizophrenia and other schizophrenia spectrum disorders was over $20 \%$, which suggests a 10- to 15-fold increase in risk (Brown et al., 2001). We also observed that a decline in IQ between childhood and adolescence was present in a markedly greater proportion of rubella exposed cases compared to rubella exposed controls, further supporting the plausibility of the association.

\section{FINDINGS FROM OTHER BIRTH COHORT STUDIES OF INFECTION}

Other birth cohort studies, utilizing databases from obstetric records have demonstrated relationships between prenatal infection and schizophrenia. An advantage of these studies is that infections that have been documented by physicians are often used to define exposure status, and they can be conducted more conveniently than studies of biomarkers, by record linkages between sources of data on exposure, including records from pregnancy and birth, and sources of data on outcomes, including psychiatric registries or direct interviews.

These studies have revealed several additional findings. In the CHDS cohort, periconceptional exposure to maternal genitalreproductive infection was shown to be associated with a fivefold increase in schizophrenia risk (Babulas et al., 2006), and second trimester exposure to maternal respiratory infection conferred a twofold elevation in risk (Brown et al., 2000). In the Copenhagen Perinatal Cohort, born 1959-1961, an association was found between maternal bacterial infections in the first and second trimesters and risk of schizophrenia, with approximately twofold increases in the effects (Sørensen et al., 2009). In a study based on data from women treated for urinary tract infections during pregnancy in Helsinki, Finland from 1947 to 1990, an interaction was observed between exposure to pyelonephritis and a family history of schizophrenia (Clarke et al., 2009).

\section{POTENTIAL CAUSAL MECHANISMS}

These findings have the potential to elucidate neurodevelopmental mechanisms by which infections or other putative risk factors may increase susceptibility to schizophrenia. For many of the infections reviewed above, it is unlikely that the effects can be explained by a direct disruption of the fetal brain by these agents given that some, such as influenza, do not cross the placenta, or others, including elevated toxoplasma IgG were observed in the absence of active infection. We first consider whether there may be a mechanism in common to different infections that has been related to schizophrenia in the birth cohort studies reviewed above, and that does not require direct fetal invasion. It is well known that virtually all infections induce the release of cytokines, molecules that orchestrate the host immune response. These include proinflammatory cytokines, such as interleukin-6 (IL-6), IL-8, and, 
TNF-alpha. The hypothesis that these molecules may mediate the effects of infection on schizophrenia risk (Gilmore and Jarskog, 1997), has been tested in many studies of maternal immune activation (MIA) in animal models (for review see Patterson, 2009). In these studies an agent known to produce MIA, such as polyinosinic:polycytidylic acid (poly I:C), which mimics a viral infection, or lipopolysaccharide (LPS), which mimics a bacterial infection are administered to pregnant rodents, and the offspring are assessed for behavioral, neurochemical, and other phenotypes observed in patients with schizophrenia. MIA exposure causes abnormalities in behaviors and neurochemical responses elicited by excess dopamine and neurophysiologic abnormalities including latent inhibition deficits, which were reversed by clozapine. MIA also led to increased sensitivity of the offspring to an antagonist of the $N$-methyl-D-aspartic acid antagonist MK-801. These findings are consistent with neurochemical abnormalities that have been robustly implicated in schizophrenia (Owen and Simpson, 1995). Intriguingly, the effects of IL-6 on such phenotypes in offspring were prevented by administration of anti-IL-6 antibody or in an IL-6 genetic knockout (Smith et al., 2007). As noted above, maternal sera elevations in two pro-inflammatory cytokines, IL-8 and TNF-alpha, were associated with schizophrenia in previous studies (Buka et al., 2001b; Brown et al., 2004b). In more recent work, maternal influenza infection was found to cause reduced cortical gray matter volume, decreased white matter in the parietal cortex, and maternal IgG was correlated with ventricular enlargement (Short et al., 2010). Prenatal immune activation also interacts with mutant DISC1 to produce alterations of social behavior, modulation of secretion of fetal inflammatory cytokines, and other effects (Abazyan et al., 2010). MIA impairs several aspects of synaptic function and synaptophysin levels, though does not cause neuronal loss, consistent with observations in postmortem schizophrenia brain (Oh-Nishi et al., 2010) and alters long-range neural synchrony (Dickerson et al., 2010).

A second possible scenario, which may co-exist with the "common mechanism" hypothesis, is that different prenatal infections may act by unique mechanisms to increase risk of schizophrenia. Each of these agents differ in their antigenicity, symptoms, and biological effects, and may therefore have differential consequences on fetal brain development relevant to the neurobiology of schizophrenia. For example, rubella is known to directly infect the fetal brain, leading to a potent inflammatory response which causes neuronal death, gliosis, and a disruption of mitosis (Brown et al., 2001); this differs from an agent such as influenza, which does not appear to cross the placenta.

Clinical studies of schizophrenia are providing further evidence that prenatal infection alters structure and function of the brain. In utero exposure to infection has been associated with executive function deficits, and larger size of the cavum septum pellucidum, a neuromorphologic marker of dysgenesis, in patients with schizophrenia (Brown et al., 2009a,b). More recent data indicates that maternal elevated interleukin- 8 is associated with ventricular enlargement in schizophrenia cases (Ellman et al., 2010) and maternal genital-reproductive infections are related to verbal memory, neuromotor, and working memory deficits (Brown et al., 2011).

\section{IMPLICATIONS OF THE FINDINGS FOR PREVENTION AND GENETICS RESEARCH}

One clear implication of these findings is that, if replicated, they suggest that straightforward public health measures may result in a reduction in the incidence of schizophrenia. Influenza vaccination, improved hygiene to prevent $T$. gondii infection, and antibiotics to treat genital/reproductive infections are strategies that are already being employed in both pregnant and non-pregnant populations. Using the population prevalences of these putative risk factors in the studies from the CHDS cohort, we calculated, for each of these infections, the attributable proportion, or the percentage of cases in the population who would not have developed the disease if the exposure were eliminated (Brown and Derkits, 2010). We found that complete elimination of each of these three classes of infections would prevent as many as 33\% of schizophrenia cases from the population. Although complete prevention of all of these infections is clearly not realistic, it nonetheless suggests that greater attention to reducing their incidence could have an appreciable effect on reduction of schizophrenia risk in the population.

While molecular genetic and genetic epidemiologic studies have great potential to elucidate the pathogenic mechanisms that lead to the disorder, it is our view (Brown and Derkits, 2010), and those of others (van Os et al., 2008) that their promise can only be fully realized by studies of gene-environment interaction. Studies of individual susceptibility genes generally have small to modest effects on risk, and interactions between genetic mutations and environmental factors have been proposed to account for the majority of liability to most complex diseases such as schizophrenia (van Os et al., 2008). Interestingly, in three large genome-wide association studies of schizophrenia, genetic variants in the extended major histocompatibility complex (MHC) reached genome-wide significance (Purcell et al., 2009; Shi et al., 2009; Stefansson et al., 2009), one of the few replicated genetic findings. These genes are critical to not only immune function, but also synaptic function, remodeling, and plasticity (Boulanger, 2009). Hence, the study of environmental factors may increase the likelihood of identifying susceptibility genes that interact with environmental exposures such as prenatal infection.

\section{SUMMARY AND DIRECTIONS FOR FUTURE RESEARCH}

Ecologic studies provided suggestive evidence that prenatal infection may be a risk factor for schizophrenia. Several birth cohort studies, which have capitalized on methodologic improvements to these earlier studies, have yielded intriguing evidence supporting this association. These infections may act via a common pathway, such as the cytokine response, unique mechanisms, or a combination of these pathways to elevate susceptibility to this disorder. Animal models have documented that MIA leads to abnormalities of brain and behavior that are consistent with phenotypes observed in schizophrenia. These findings have clear public health implications given that interventions already exist to prevent and treat these infections.

We suggest several approaches aimed at confirming and elaborating upon the findings to date. First, it will be necessary to replicate these results in other samples, ideally in other birth cohorts with prospective measures of infection. Second, we suggest 
that future studies examine both prenatal infection and putative susceptibility genes within the same cohorts in order to investigate gene-environment interaction. This may increase the probability of identifying both in utero infectious microbes and genetic mutations that increase risk of schizophrenia. Third, we advocate for further translational research aimed at validating infection-induced phenotypes and exploring causal mechanisms of this disorder. Finally, we suggest that interdisciplinary alliances between experts in epidemiology, molecular and clinical neuroscience, and genetics will allow us to fully realize the promise of

\section{REFERENCES}

Abazyan, B., Nomura, J., Kannan, G., Ishizuka, K., Tamashiro, K. L., Nucifora, F., Pogorelov, V., Ladenheim, B., Yang, C., Krasnova, I. N., Cadet, J. L., Pardo, C., Mori, S., Kamiya, A., Vogel, M. W., Sawa, A., Ross, C. A., and Pletnikov, M. V. (2010). Prenatal interaction of mutant DISC1 and immune activation produces adult psychopathology. Biol. Psychiatry 68, 1172-1181.

Babulas, V., Factor-Litvak, P., Goetz, R., Schaefer, C. A., and Brown, A. S. (2006). Prenatal exposure to maternal genital and reproductive infections and adult schizophrenia. Am. J. Psychiatry 163, 927-929.

Boulanger, L. M. (2009). Immune proteins in brain development and synaptic plasticity. Neuron 64, 93-109.

Brown, A. S., Begg, M. D., Gravenstein, S., Schaefer, C. A., Wyatt, R. J., Bresnahan, M., Babulas, V. P., and Susser, E. S. (2004a). Serologic evidence of prenatal influenza in the etiology of schizophrenia. Arch. Gen. Psychiatry 61, 774-780.

Brown, A. S., Hooton, J., Schaefer, C. A., Zhang, H., Petkova, E., Babulas, V., Perrin, M., Gorman, J. M., and Susser, E. S. (2004b). Elevated maternal interleukin-8 levels and risk of schizophrenia in adult offspring. Am. J. Psychiatry 161, 889-895.

Brown, A. S., Cohen, P., HarkavyFriedmen, J., Babulas, V., Malaspina, D., Gorman, J. M., and Susser, E. S. (2001). A. E. Bennett Research Award. Prenatal rubella, premorbid abnormalities, and adult schizophrenia. Biol. Psychiatry 49, 473-486.

Brown, A. S., Deicken, R. F., Vinogradov, S., Kremen, W. S., Poole, J. H., Penner, J. D., Kochetkova, A., Kern, D., and Schaefer, C. A. (2009a). Prenatal infection and cavum septum pellucidum in adult schizophrenia. Schiophr. Res. 108, 285-287.

Brown, A. S., Vinogradov, S., Kremen, W. S., Poole, J. H., Deicken, R. F., Penner, J. D., Mckeague, I. W.,
Kochetkova, A., Kern, D., and Schaefer, C. A. (2009b). Prenatal exposure to maternal infection and executive dysfunction in adult schizophrenia. Am. J. Psychiatry 166, 683-690.

Brown, A. S., and Derkits, E. J. (2010). Prenatal infection and schizophrenia: a review of epidemiologic and translational studies. Am. J. Psychiatry 167, 261-280.

Brown, A. S., Schaefer, C. A., Queensberry, C. P. Jr., Liu, L., Babulas, V. P., and Susser, E. S. (2005). Maternal exposure to toxoplasmosis and risk of schizophrenia in adult offspring. Am. J. Psychiatry 162, 767-773.

Brown, A. S., Schaefer, C. A., Queensberry, C. P. Jr., Shen, L., and Susser, E. S. (2006). No evidence of relation between maternal exposure to herpes simplex virus type 2 and risk of schizophrenia? Am. J. Psychiatry 163, 2178-2180.

Brown, A. S., Schaefer, C. A., Wyatt, R. J., Goetz, R., Begg, M. D., Gorman, J. M., and Susser, E. S. (2000). Maternal exposure to respiratory infections and adult schizophrenia spectrum disorders: a prospective birth cohort study. Schizophr. Bull. (Bp)

Brown, A. S., Vinogradov, S., Kremen, W. S., Poole, W. S., Bao, Y., Kern, D., and McKeague, I. W. (2011). Association of maternal genital and reproductive infections with verbal memory and motor deficits in adult schizophrenia. Psychiatry Res. 2011, 179-186.

Buizer-Voskamp, J. E., Muntjewerff, J. W., Genetic Risk and Outcome in Psychosis (Group) Consortium, Strengman, E., Sabatti, C., Stefansson, H., Vortsman, J. A., and Ophoff, R. A. (2011). Genome-wide (analysis) shows increased frequency of copy number variation deletions in Dutch schizophrenia patients. Biol. Psychiatry 70, 655-662.

Buka, S. L., Cannon, T. D., Torrey, E. F., Yolken, R. H., and Collaborative Study Group on the Perinatal Origins of Severe Psychiatric Disorders. 26, 287-295.

identifying infectious and other environmental and genetic origins of schizophrenia.

\section{ACKNOWLEDGMENTS}

This manuscript was supported by the National Institute of Mental Health (NIMH) 2K02-MH065422 (Alan S. Brown) and a National Alliance for Research on Schizophrenia and Depression (NARSAD) Independent Investigator Award (Alan S. Brown). The authors wish to acknowledge Jacky Chow for his technical contributions on this manuscript.

(2008). Maternal exposure to herpes simplex virus and risk of psychosis among adult offspring. Biol. Psychiatry 63, 809-815.

Buka, S. L., Tsuang, M. T., Torrey, E. F., Klebanoff, M. A., Bernstein, D. and Yolken, R. H. (2001a). Maternal infection and subsequent psychosis among offspring. Arch. Gen. Psychiatry 58, 1032-1037.

Buka, S. L., Tsuang, M. T., Torrey, E. F., Klebanoff, M. A., Wagner, R. L., and Yolken, R. H. (2001b). Maternal cytokine levels during pregnancy and adult psychosis. Brain Behav. Immun. 15, 411-420.

Clarke, M. C., Tanskanen, A., Huttunen, M., Whittaker, J. C., and Cannon, M. (2009). Evidence for an interaction between familial liability and prenatal exposure to infection in the causation of schizophrenia. Am. J. Psychiatry 166, 1025-1030.

Dickerson, D. D., Wolff, A. R., and Bilkey, D. K. (2010). Abnormal long-range neural synchrony in a maternal immune activation animal model of schizophrenia. J. Neurosci. 30, 12424-12431.

Ellman, L. M., Deicken, R. F., Vinogradov, S., Kremen, W. S., Poole, J. H., Kern, D. M., Tsai, W. Y., Schaefer, C. A., and Brown, A. S. (2010). Structural brain alterations in schizophrenia following fetal exposure to the inflammatory cytokine interleukin8. Schizophr. Res. 121, 46-54.

Gejman, P. V., Sanders, A. R., and Kendler, K. S. (2011). Genetics of schizophrenia: new findings and challenges. Annu. Rev. Genomics Hum. Genet. 12, 121-144.

Gilmore, J. H., and Jarskog, L. F. (1997). Exposure to infection and brain development: cytokines in the pathogenesis of schizophrenia. Schizophr. Res. 24, 365-367.

Mortensen, P. B., Nørgaard-Pedersen, B., Waltoft, B. L., Sørensen, T. L., Hougaard, D., Torrey, E. F., and Yolken, R. H. (2007). Toxoplasma gondii as a risk factor for earlyonset schizophrenia: analysis of filter paper blood samples obtained at birth. Biol. Psychiatry 61, 688-693.

Mortensen, P. B., Pedersen, C. B. Hougaard, D. M., NørgaardPetersen, B., Mors, O., Børglum, A. D., and Yolken, R. H. (2010). A Danish National Birth Cohort study of maternal HSV-2 antibodies as a risk factor for schizophrenia in their offspring. Schizophr. Res. 122, 257-263.

Oh-Nishi, A., Obayashi, S., Sugihara, I., Minamimoto, T., and Suhara, T. (2010). Maternal immune activation by polyriboinosinicpolyribocytidilic acid injection produces synaptic dysfunction but not neuronal loss in the hippocampus of juvenile rat offspring. Brain Res. 1363, 170-179.

Owen, F., and Simpson, M. D. C. (1995). "The neurochemistry of schizophrenia," in Schizophrenia, eds S. R. Hirsch and D. R. Weinberger (Oxford: Blackwell Science Ltd.), 358-378.

Patterson, P. H. (2009). Immune involvement in schizophrenia and autism: etiology, pathology, and animal models. Behav. Brain Res. 204, 313-321.

Purcell, S. M., Wray, N. R., Stone, J. L. Visscher, P. M., O’Donovan, M. C., Sullivan, P. F., and Sklar, P. (2009). Common polygenic variation contributes to risk of schizophrenia and bipolar disorder. Nature 460, 748-752.

Remington, J. S., and Klein, J. O. (2006). Infectious Diseases of the Fetus and Newborn Infant, 6th Edn. Philadelphia: Elsevier Saunders.

Riley, B. P., and Kendler, K. S. (2005). "Schizophrenia: genetics," in Kaplan and Sadock's Comprehensive Textbook of Psychiatry, 8th Edn, eds B. J. Sadock and V. A. Sadock (Philadelphia, PA: Lippincott Williams \& Wilkins), 1354-1371.

Rothman, K. J., and Greenland, J. O. (1998). Modern Epidemiology. Philadelphia: Lippincott Williams \& Williams. 
Schwarts, S., and Susser, E. (2006). "Twin studies of heritability," in Psychiatric Epidemiology, eds E. Susser, S. Schwartz, A. Morabia, and E. J. Bromet (New York, NY: Oxford University Press), 375-388.

Shi, J., Levinson, D. F., Duan, J., Sanders, A. R., Zheng, Y., Pe'er, I., Dudbridge, F., Holmans, P. A., Whittemore, A. S., Mowry, B. J., Olincy, A., Amin, F., Cloninger, C. R., Silverman, J. M., Buccola, N. G., Byerley, W. F., Black, D. W., Crowe, R. R., Oksenberg, J. R., Mirel, D. B., Kendler, K. S., Freedman, R., and Gejman, P. V. (2009). Common variants on chromosome 6p22.1 are associated with schizophrenia. Nature 460, 753-757.

Short, S. J., Lubach, G. R., Karasin, A. I., Olsen, C. W., Styner, M., Knickmeyer, R. C., Gilmore, J. H., and Coe, C. L. (2010). Maternal influenza infection during pregnancy impacts postnatal brain development in the rhesus monkey. Biol. Psychiatry 67, 965-973.

Smith, S. E., Li, J., Garbett, K., Mirnics, K., and Patterson, P. H.
(2007). Maternal immune activation alters fetal brain development through interleukin-6. J. Neurosci. 27, 10695-10702.

Sørensen, H. J., Mortensen, E. L., Reinisch, J. M., and Mednick, S. A. (2009). Association between prenatal exposure to bacterial infection and risk of schizophrenia. Schizophr. Bull. 35, 631-637.

Stefansson, H., Ophoff, R. A., Steinberg, S., Andreassen, O. A., Cichon, S., Rujescu, D., Werge, T., Pietilainen, O. P., Mors, O., Mortensen, P. B., Siguurdsson, E., Gustafsson, O., Nyegaard, M., Tuulio-Henriksson, A., Ingason, A., Hansen, T., Suvisaari, J., Lonngvist, J., Paunio, T., Borglum, A. D., Hartmann, A., Fink-Jensen, A., Nordentoft, M., Hougaard, D., Norgaard-Pedersen, B., Bottcher, Y., Olesen, J., Breuer, R., Moller, J. J., Giegling, I., Rasmussen, H. B., Timm, S., Mattheisen, M., Bitter, I., Rethelyi, J. M., Magnusdottir, B. B., Sigmundsson, T., Olason, P., Masson, G., Gulcher, J. R., Haraldsson, M., Fossdal, R., Thorgeirsson, T. E., Thorsteinsdottir, U., Ruggeri, M.,
Tosato, S., Franke, B., Strengman, E., Kiemeney, L. A., Genetic Risk and Outcome in Psychosis (GROUP), Melle, I., Djurovic, S., Abramova, L., Kaleda, V., Sanjuan, J., de Frutos, R., Bramon, E., Vassos, E., Fraser, G., Ettinger, U., Picchioni, M., Walker, N., Toulopoulou, T., Need, A. C., Ge, D., Yoon, J. L., Shianna, K. V., Freimer, N. B., Cantor, R. M., Murray, R., Kong, A., Golimbet, V., Carracedo, A., Arango, C., Costas, J., Jonsson, E. G., Terenius, L., Agartz, I., Petursson, H., Nothen, M. M., Rietschel, M., Matthews, P. M., Muglia, P., Peltonen, L., St Clair, D., Goldstein, D. B., Stefansson, K., Collier, D. A. (2009). Common variants conferring risk of schizophrenia. Nature 460 744-747.

van Os, J., Rutten, B. P., and Poulton, R. (2008). Gene-environment interactions in schizophrenia: review of epidemiological findings and future directions. Schizophr. Bull.34, 1066-1082.

Waddington, J. L. (1993). Schizophrenia: developmental neuroscience and pathobiology. Lancet 341, 531-536.

Conflict of Interest Statement: The author declares that the research was conducted in the absence of any commercial or financial relationships that could be construed as a potential conflict of interest.

Received: 17 June 2011; accepted: 02 November 2011; published online: 23 November 2011.

Citation: Brown AS (2011) Exposure to prenatal infection and risk of schizophrenia. Front. Psychiatry 2:63. doi: 10.3389/fpsyt.2011.00063

This article was submitted to Frontiers in Molecular Psychiatry, a specialty of Frontiers in Psychiatry.

Copyright (C) 2011 Brown. This is an open-access article subject to a nonexclusive license between the authors and Frontiers Media SA, which permits use, distribution and reproduction in other forums, provided the original authors and source are credited and other Frontiers conditions are complied with. 